The specificity of the employment relationship Exploring the micro-foundations of the firm

Helena Lopes Dezembro de 2015

WP n.0 2015/09

DOCUMENTO DE TRABALHO

WORKING PAPER

DINAMIP'CET

CENTRO DE ESTUDOS SOBREA AMUDANCA
SOCIOECONÓMICA E O TERRITÓHIO

ISCTE-IUL 


\title{
DINAMIR'CET
}

CENTRO DE ESTUDOS SOBREA MUDA
SOCIOECONOMICA E OTERAITORIO

ISCTE-IUL

\section{The specificity of the employment relationship - Exploring the micro-foundations of the firm}

\author{
Helena Lopes * \\ WP n. $\circ 2015 / 09$
}

DOI: 10.15847/dinamiacet-iul.wp.2015.09

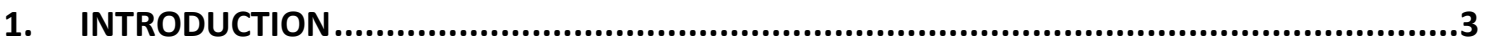

\section{THE STANDARD HUMAN FACTOR BEHIND MAINSTREAM THEORIES OF THE FIRM:}

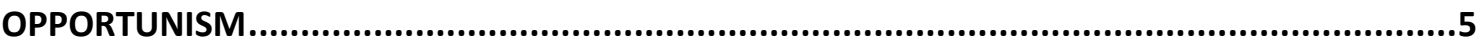

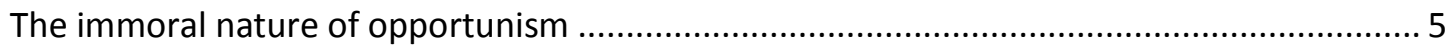

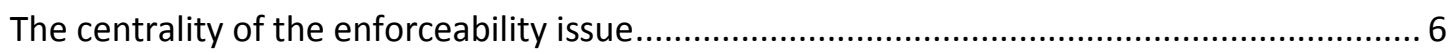

3. THE NEW HUMAN FACTOR SUGGESTED FOR MAINSTREAM THEORIES OF THE FIRM:

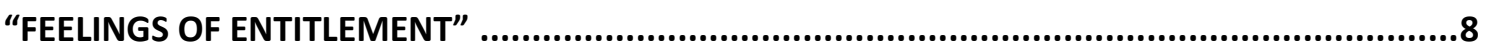

Hart and Moore's theory of contracts as reference points: the very "non-standard" nature of

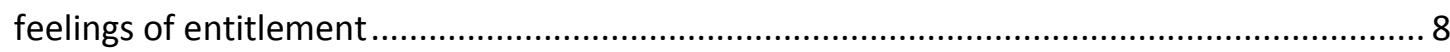

Feelings of entitlement, norms and relational contracts - going beyond Hart and More (2008)

4. THE TWO UNIQUE SPECIFICITIES OF THE EMPLOYMENT RELATIONSHIP ......................15

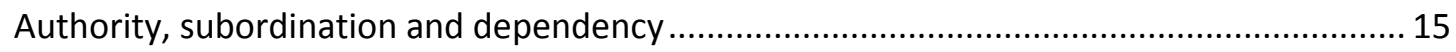

The specificity of the object being exchanged: work ......................................................... 16

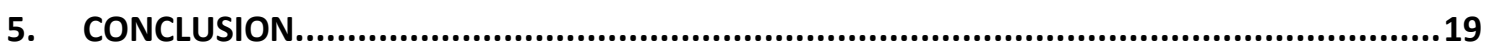

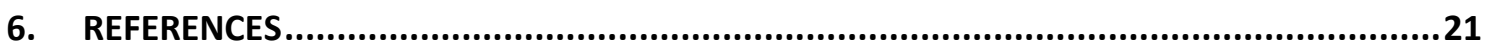

* DINÂMIA'CET - IUL e Instituto Universitário de Lisboa (ISCTE-IUL).

Corresponding author e-mail Helena.lopes@iscte.pt

Av. Das Forças Armadas, 1649-026 Lisboa - Portugal. Contact: +351 217903434. 


\title{
The specificity of the employment relationship - Exploring the micro-foundations of the firm
}

\begin{abstract}
:
We begin by examining the human traits that the leading mainstream economic theories of the firm consider relevant to understand the functioning of firms. We point out that the opportunism assumption (Williamson, 1975) differs from the "feelings of entitlement" assumption (Hart and Moore, 2008) which acknowledges both the negative and positive facets of moral behavior. Our thesis is that such divergence in the micro-foundations of the firm reflects the absence of an explicit and sound comprehension of why is the use of "human assets" more efficient in organizations than in markets. Such comprehension involves inquiring the specificity of the employment relationship, which we argue goes beyond authority/subordination to include a normative and relational dimension. The unique specificity of the employment relationship lies in the combination of i) some traits of human behavior with ii) the particular institutional setting in which work is performed and iii) the nature of work as a specific human activity. In any case, to soundly understand the employment relationship, one must go beyond the calculative abilities of homo economicus and endow him with moral abilities.
\end{abstract}

JEL: A13, D23, J80

KEYWORDS: micro-foundations of the firm, employment relationship, homo economicus 
The trick in every case is to understand what is being contracted for

Oliver Williamson (1982/1975:ix)

\section{INTRODUCTION}

In the preface to the 1983 Edition of Markets and Hierarchies (Williamson, 1975) Oliver Williamson explains the success and relevance of the transaction cost theory of the firm by the fact that it is grounded on "human nature as we know it". Contrary to standard economics, which he censures for ignoring the "human factors", he forcefully believes that one cannot understand the problems of economic organization without taking the basic human attributes into account. These are, in his view, opportunism (on which we focus here) and bounded rationality.

More than thirty years later Oliver Hart and John Moore (2008:3) recognize that the property rights theory of the firm, which they launched in the late $80 \mathrm{~s}$, suffers from "foundational weaknesses". In order to develop a more general and compelling theory of the firm, they introduced, just like Williamson did, new behavioral elements into their model. The human attributes selected as relevant by Hart and Moore are the "feelings of entitlements" generated by ex ante contracts, feelings which, when aggrieved, give rise to shading costs.

The behavioral micro-foundations that ground the leading mainstream economic theories of the firm hence are strikingly different. A first aim of the present paper is to elicit in greater detail the conception of human behavior that underlies the assumptions of opportunism and feelings of entitlement. Our argument is that the human factors put forward by each theory refer to profoundly distinct, if not opposite, human traits, which is very perplexing.

Our thesis is that such divergence in the micro-foundations of the firm reflects the absence of an explicit and sound comprehension of why is the use of "human assets" more efficient in organizations than in markets - that is, why is the employment relationship more efficient than independent contracting. Such comprehension involves inquiring the specificity of the employment relationship, which we argue is very much related to the human traits considered to be relevant in work organizations. As put by Cheung (1983:3), a firm emerges when an input owner makes the option of "entering into a contractual arrangement surrendering the use of his input to an agent in exchange for an income", ie, there are no firms without employees. The constitutive and defining feature of firms is their grounding on the specific institution of the employment relationship. This logically imply that to each theory of the firm should be associated a conception of the employment relationship. 
This is not the case for many economic theories of the firm, though. If Ronald Coase (1937) placed the employment contract - and related authority/subordination relationship - at the very core of his theory of the firm, Alchian and Demsetz (1972) denied that employment contracts differ in any meaningful sense from independent contracting. The very term "employment" hardly appears in Gibbons (2005)'s comparison and formalization of the leading economic theories of the firm. In the same vein, Hart and Holmstrom (2010:510), in their authoritative paper on the theory of the firm, recognize that "our model [of the firm] does not currently have workers".

The foregoing considerations show that mainstream theories of the firm are pitched at such a level of generality that they do not acknowledge the specificity of the employment relationship. Indeed, Williamson declares that opportunism and bounded rationality are present in all economic transactions, not just the employment contract, and Hart (2008:409) states that the feelings of entitlement and respective "aggrievement costs arise under employment as well as under independent contracting". That is, no real, unique specificity is recognized to the employment relationship. We claim, by contrast, that it is the very specificities of the employment relationship that account for why organizations are more efficient than markets.

Instead of the conventional question addressed by mainstream theories of the firm, ie, "which transactions are more efficiently conducted in a firm than in a market?", our inquiry focuses on "why are some transactions, namely the transaction of work, more efficiently conducted in a firm than a market?". Coase's (1937), Simon's (1951), Williamson's (1975) and their followers' response is well-known: coordination by fiat allows a reduction in transaction costs and enhances adaptation to unforeseen circumstances. Our argument is that authority and subordination alone would not yield such favorable outcomes.

The second aim of the present paper is hence to outline a more comprehensive account of the singular specificities of the employment relationship when compared to independent contracting. Beyond authority/subordination, other aspects of the employment relationship, largely ignored in received theories of the firm, must be acknowledged, namely its deeply normative nature, its encompassing a relational and personal dimension and, last but not least, the fact that the object of the exchange is not a commodity but work, ie, a meaningful human activity. The unique specificity of the employment relationship lies in the combination of i) some traits of human behavior with ii) the particular institutional setting in which work is performed and iii) the nature of work as a specific human activity.

We build on Williamson (1975) and Hart and More (2008) - hereafter HM2008 - in the second and third section, respectively, to identify and critically examine the human factors considered 
relevant for the analysis of the employment relationship in these two particular theories of the firm. Section four investigates the two unique features of the employment relationship: first subordination, ie, inequality of bargaining power and dependency, and second the specificity of the object being exchanged, namely work, which no conception of the employment relationship can discard. Section five concludes.

\section{THE STANDARD HUMAN FACTOR BEHIND MAINSTREAM THEORIES OF THE FIRM: OPPORTUNISM}

\section{The immoral nature of opportunism}

The statute of opportunism in relation to utility-maximization is less than clear-cut. The theory of rational choice (utility maximization) is assumedly axiologically neutral - ie, amoral because it only sets out an axiomatic framework for choice. But actually, most economic models introduce ad hoc assumptions into utility functions that give utility a substance. In most cases, utility is equated to self-centered or pecuniary motives, but behavioral economics and its social preferences models, for instance, endow economic agents with more or less moral preferences. Axiological neutrality hence ends up being more an ideological or utopian veil than an actual trait of utility models.

Williamson (1975) refers at the beginning of his book that opportunism is a "variety of self-seeking assumption [...] akin to the prevailing behavioral assumptions employed throughout microeconomics" (p. 7) but he then says that opportunism "refers to a lack of candor or honesty in transactions, to include self-interest with guile" (p. 9). He draws a moral spectrum in which opportunism occupies the immoral end - it involves making false and self-disbelieved promises; stewardship behavior occupies the moral end - people can be trusted to keep their word; and instrumental behavior is located at the middle - a morally neutral behavior which does not deliberately manipulates other parties to further own interests (p.26-27).

Opportunism was adopted by all contractual theories of the firm as the relevant assumption regarding behavior within firms. Hart (2002), for example, maintains that although firms would have difficulty surviving in a society in which honesty would not be taken seriously one cannot assume that employers or employees can be trusted to keep their word. He explicitly states that purely self-interested parties are not trustworthy parties (p. 1703) because there will always be an incentive to break a promise. Furthermore, he associates keeping one's promise to "irrational" behavior (p. 1705). In sum, contrary to the abstract amoral utility-maximization

DINÂMIA'CET - IUL, Centro de Estudos sobre a Mudança Socioeconómica e o Território 
principle, opportunism, which became the grounding behavioral assumption of all mainstream theories of the firm ${ }^{1}$, clearly entails immoral behavior. Fehr et al (2011) who, like all economists, avoid using moral qualification, refer to opportunism as a "strong self-serving behavior bias".

Williamson (1975) argues that when institutional design is at stake the only relevant behavioral assumption to adopt is presuming that human agents are prone to be opportunistic. His concept of "atmosphere" nonetheless acknowledges that the functioning of organizations may be grounded on positive moral features, if and when the attitudes and preferences of the organization members allow for it. Contrary to market exchange, which he considers tends to encourage calculative relations, internal organizations are "able to make allowance to quasimoral involvements among the parties" (p. 38). But he then removes these "extraeconomic considerations" from his analytical developments.

Williamson notes that the "quasimoral involvements" have special relevance where employment relationships are involved but, since he conceives the employment relationship primarily as a specific-investment relationship, he is lead to emphasize again opportunistic behavior. This results in leaving the center stage to the rent-seeking and hold-up phenomena, subsequently extensively addressed in the literature. To sum up, the approach of the employment relationship espoused by Williamson highlights opportunism, ie, the more or less immoral utility calculations of employees; anything else is discarded as utopian.

\section{The centrality of the enforceability issue}

The behavioral assumption of opportunism, combined with uncertainty about the states of nature, obviously raise a major enforcement issue. Williamson (1975:7) strongly emphasizes that it is not uncertainty individually that gives rise to exchange difficulties but rather its joining with opportunism; similarly Holmstrom (1999) declares that the moral hazard or free riding problems stem from imperfect performance measurement, ie uncertainty about the state of the world combined with suspicion about the amount of effort provided. Note that the enforcement issue was never mentioned by Coase (1937) who seemed to take obedience by employees for granted.

\footnotetext{
${ }^{1}$ Like transaction costs and incomplete contracts theories, agency or incentive theory is also explicitly grounded on opportunism, as revealed by its core building concept - that of agency costs - and its focus on moral hazard. We recall that Oliver Williamson is the leading scholar of the transaction cost theory and Oliver Hart the leading scholar of first, the property rights, and then the incomplete contracts theory of the firm.
} 
It may be relevant at this point to explicitly define what we are speaking about. The employment relationship is based on an employment contract which, like all contracts are defined as "an agreement under which two parties make reciprocal commitments in terms of their behavior - a bilateral coordination arrangement" (Brousseau and Glachant, 2002:3). (Note the moral flavor of the terms "reciprocal commitments"). The employment contract is specifically defined by a particular coordination arrangement, namely authority/subordination. Entering into an employment contract means agreeing "to obey the directions of [managers] within certain limits" (Coase, 1937:39). What is at stake is obedience, on the one hand, ie, the compliance of the commitment to follow directions, but also, on the other hand, the specification of what might "within certain limits" entail - an issue to which we turn in section four.

Authority/subordination is an appropriate coordination mode when contracts are incomplete, ie, when they cannot specify which future events might occur and which adaptations should be made if they do occur. There are several sources of incompleteness in employment contracts, raising various types and degrees of enforcement issues, which call for differentiated contractual arrangements (Bolton and Dewatripont, 2012). For example, in incomplete contracts theory, economic variables may be observable ex post to the contracting parties but if they cannot be verified by outsiders - such as a court - they are said to be unverifiable and consequently non-contractible and non-enforceable. Hart (2002:1702) illustrates his point: a contract between an employer and an employee may specify that the former gives the latter a bonus in case of good performance; even if both observe ex post that the employee performed well, the contract may not be enforced - the employer may not pay the bonus without incurring any sanction - because courts are not able to judge the quality of an employee's performance. In this case, the employee can never be protected against the employer's opportunistic behavior.

As for employee's opportunism, a distinction emphasized by Williamson (1975:69) is important mentioning. Each employee always has to choose between providing "perfunctory" or "consummate" performance. Performing perfunctorily means carrying out the assigned tasks at the minimally acceptable level of effort while performing consummately means adopting a positive attitude, that is, using one's abilities at work without deliberate restraint. The incomplete contracts literature considers that only perfunctory performance can be enforced; 
consummate performance is always discretionary (Hart, 2008:407) - but is crucial for organizational efficiency ${ }^{2}$.

Before closing this section, in which we intended to highlight that in mainstream theories it is immoral behavior that primarily characterizes behavior in the employment relationship - which raises a major enforceability issue - we would like to contrast the economics' with the law's perspective. Masten (1988) denounces economics' downplay of the role of the law in defining the firm. He emphasizes that, unlike commercial transactions, the employment contract embodies a unique set of obligations and responsibilities: "upon entering an employment relationship, every employee accepts an implied duty to 'yield obedience to all reasonable rules, orders, and instructions of the employer' [...] In addition to obedience, an employer has the right to expect loyalty, respect, and faithfulness from his employees" (Masten, $1988: 185,187$, our italics). That is, the enforceability issue is to be resolved, in labor law, by the moral abilities or dispositions of employees. The counterpart of the employees' duties is the responsibility assigned to employers for the outcomes of the employees' acts. There is hence a sharp contrast between the rarely explicit assumption of negative moral behavior in the mainstream conception of the employment relationship - the word moral is as much avoided as possible - and the explicit reference to positive moral traits in the law of employment.

\section{THE NEW HUMAN FACTOR SUGGESTED FOR MAINSTREAM THEORIES OF THE FIRM: "FEELINGS OF ENTITLEMENT"}

\section{Hart and Moore's theory of contracts as reference points: the very "non-standard" nature of feelings of entitlement}

The objective of HM2008 is to advance the theory of the firm by providing a formal model of "haggling" costs. Note that haggling costs, as underlined by Gibbons (2005:218), may also be defined as "post-contractual opportunism". Hart (2008) argues that haggling costs had been improperly side-stepped in the literature: transaction cost theory contented itself with assuming their existence and relied on relationship-specific investments to explain why firms are more efficient than markets, that is, why haggling costs are limited. In turn, the property rights theory of the firm, launched in the 1970s by Hart and co-authors and which subsequently evolved into the incomplete contract theory of the firm, avoided dealing with haggling costs by assuming

\footnotetext{
2 Though agency theory never refers the notion of "consummate" performance, we may speculate that it is in fact its irreducibly discretionary character that explains why agency theory sees employers as being at the mercy of their employees' opportunism - which contrasts with the commonly held reverse perception - and that justifies its emphasis on incentives' alignment.
} 
costless ex post negotiation. In fact, HM2008's endeavor can be seen as an attempt to explain why haggling costs/opportunistic behavior emerges. To do this, they introduce "unexpected human traits" into mainstream theory.

A key distinctive element of HM2008's model is it being based on the assumption that only perfunctory (basic) performance is contractible. Consummate (exemplary) performance, which, they emphasize, is what is in "the spirit of the contract" ${ }^{3}$ (HM2008: 3), is not enforceable. They further assume that performing consummately is not significantly more costly than performing perfunctorily, ie, employees may actually enjoy providing consummate performance.

It is precisely to explain why employees perform consummately rather than perfunctorily that they introduce "non-standard behavioral elements" into their model: employees ${ }^{4}$ provide consummate performance if they feel well treated (positive reciprocity) but not if they feel badly treated (negative reciprocity) (Hart, 2008: 407; Hart and Moore, 2008, p.7). Whether employees feel well or badly treated depends on whether they get what they believe they are entitled to; if they don't get it, they feel aggrieved and shade. The problem the model is supposed to solve is that the parties may diverge in their valuation of the action or activity contracted for. An employee may convince herself that her contribution is very valuable and that she deserves and is entitled to being highly rewarded but the employer may have a different valuation. Employees "shade" on consummate performance in proportion to the amount they feel aggrieved. Aggrievement and shading costs are like haggling costs.

The core idea of the contracts as reference points' model is the following: the contracting parties' sense of entitlement is determined by the (incomplete) contract they write ex ante. This is the sense in which a contract is a reference point. HM2008 analyze the conditions under which an employment contract (one in which the buyer chooses the method of production) is preferred to independent contracting (in which the seller chooses the method). In the model, the contracting parties meet in a competitive (labor) market at date 0 , in which they write a contract (the price is fixed, equal to that set in the competitive market, and they decide on the contract type) and the transaction takes actually place at date 1 . Because there is uncertainty about the future state of the world, ie, they cannot specify the method of production or tasks to be performed, they write an incomplete contract. The state of the world becomes

\footnotetext{
${ }^{3}$ It is worth noting that consummate performance is indeed what is assumed in labor law, which explicitly acknowledges that it involves loyalty and compliance with commitments.

${ }^{4}$ HM2008 use this reasoning to account for the behavior of contracting parties in general, not just employees' behavior. But the employment contract fits well in their framework since it fixes wages in advance and leaves discretion to the employer to choose tasks and for the employee to choose between consummate and perfunctory performance ex post. We focus only on the employment contract case here.
} 
known - assumedly by both parties without any disagreement on its interpretation - at date 1 . The parties decide to choose an employment rather than an independent contract at stage 0 depending on the objective productive surplus plus the aggrievement costs they calculate will be generated by each option. Aggrievement causes psychic loss to the party experiencing it and the party offsets this by shading, ie, by hurting the other party through performing perfunctorily. The role of the ex ante contract is to minimize aggrievement and hence shading costs by embodying and restraining what parties feel entitled to - parties only feel entitled to the best outcome they may reach within the outcomes stipulated in the contract and do not consider outcomes outside the contract.

Laboratorial experiments have been specifically designed to verify whether HM2008 behavioral assumptions are empirically justified. The evidence reported in Fehr et al (2011) supports the view that a contract concluded in a competitive ex ante market functions as a reference point for ex post transactions, but when the contract terms are determined in a noncompetitive way, HM2008 predictions about shading behavior in rigid contracts do not hold (rigid contracts do not help to avoid shading anymore). This shows that it is not only the terms of the contract that matter but also the competitiveness of the environment in which it was concluded (Fehr et al, 2009). Therefore, the assumption that ex ante contracts are negotiated under competitive conditions, besides eliminating possible disagreement on prices at stage 0 , considerably limits the scope of validity of the model.

Fehr et al $(2011,2009)$ relate the behavioral elements introduced in HM2008 to the behavioral economics literature, namely theories of inequity aversion, fairness theories and reciprocity models. They explain shading behavior by the fact - observed in countless experiments and routinely assumed in social preferences models - that people are willing to engage in costly behavior - perfunctory performance in the case at hand - to punish inappropriate or unfair behavior. Perceived payoff inequalities trigger shading on performance in order to mitigate inequality. The feelings of entitlement assumption hence amounts to include in the parties' utility functions social considerations and fairness concerns. This is a point worth emphasizing for the purpose of the present paper: whilst all mainstream theories of the firm are grounded on the negative moral traits of humans, HM2008 puts positive moral traits, or at least moral abilities, forward in their attempt to provide firmer micro-foundations for the theory of the firm.

However, Fehr et al (2011) draw attention to two notable differences between HM2008 and the fairness literature. First, HM2008's assumption that each party feels entitled to the most favorable outcome permitted by the contract supposes a self-serving bias stronger than is 
usually presumed in fairness models. That is, the extent of opportunism assumed in HM2008 is overrated when compared to experimental findings. But the most crucial difference concerns the key HM2008's assumption that people perceive outcomes of a competitive bargaining process (wages in the case at hand) to be acceptable or fair, an assumption confirmed by experimental findings. This means that outcomes of a competitive process may also generate consummate behavior. By contrast, the behavioral literature assumes, in the gift exchange experiments in particular, that consummate performance might only be triggered by the employer generosity, not outcomes of competitive processes. The experimental testing of HM2008's model showed that employers "can circumvent the punishment for unequal outcomes by delegating the determination of the outcome to the forces of a competitive market" (Fehr et al, 2011:521). ${ }^{5}$

Feelings of entitlement, norms and relational contracts - going beyond Hart and More (2008)

A striking inconsistency comes out of Hart's works. He his Norms and the theory of the firm paper, he claims that although norms are very important in the real world, incorporating them into the theory of the firm does not advance the understanding of firms nor does it lead to very different predictions (2002:1701). Indeed, the word norms never appear in HM2008. Yet, feelings of entitlement can hardly be conceived of without acknowledging their grounding on norms - norms, not preferences.

An interpretation of HM2008 that explicitly highlights its normative character is provided by Akerlof (2010). Akerlof defines norms as "views as to what people should do. Norms matter because they determine what people consider to be fair, and when individuals feel badly treated, they become angry" (Akerlof, 2010:1). This is just what HM2008 assume: the contract signed by the parties at stage 0 determines what they feel entitled to and thereby what may make them angry or aggrieved ex post. In Akerlof (2010)'s reading, contracts constitute reference points because they establish a norm that the parties should meet their terms. He develops a two-period psychological game to give foundations for HM2008 aggrievement model in which a party's feelings of entitlement translate into her feeling that the other party has a duty to behave in a given way. Like in HM2008, the shading of performance is viewed as a punishment of the other party. In HM2008, a party A is punished for not providing a party B the outcome party B feels she deserves. Akerlof (2010) rephrases the situation as party B punishing party A because she perceives that party A is not complying with her duty.

\footnotetext{
${ }^{5}$ We may note that this is the basic strategy of neo-liberal ideology. The employment relationship evolved along the $20^{\text {th }}$ century as a typical non-competitive circumstance in which employment law protects employees from the forces of the market, but the unfortunate trend of recent decades is precisely the shift towards a less protective setting.
}

DINÂMIA'CET - IUL, Centro de Estudos sobre a Mudança Socioeconómica e o Território 
Along with arguing that contracts establish "internal" norms, Akerlof (2010) also acknowledges, and this is a different point, that norms external to the contract also matter to understanding how the terms of a contract are to be met. In sum, Akerlof (2010) sheds light on and shows the extent to which HM2008's argument, which is entirely depicted in contractual terms, actually relies on the normative, not merely contractual dimensions of human behavior.

That contracts are pervaded by internal norms and embedded in social norms is the issue addressed in the relational contract law literature ${ }^{6}$, which emphasizes that "the first thing to note about contract is the fact that it concerns social behavior [...] A contract is an edifice partly built by the parties but also partly built by society" (Macneil, quoted in Campbell, 2001:7, 8). If HM2008 focus on the (internal) terms generated by ex ante contracts, the introduction of the "feelings of entitlement" ingredient actually involves broader social and moral norms, namely fairness and reciprocity, terms they indeed frequently use in developing their argument.

The HM2008 ex ante contract is not established between ontologically isolated individuals but between subjects endowed with different subjective valuations of given outcomes, and the contract generates and triggers an inter-subjective and normative reality that will guide their behavior and orient their judgment of what is the proper, acceptable behavior to expect ${ }^{7}$. Contracts as conceived by HM2008 are relational contracts in the sense that the extent to which they are complied with is interpreted by the contracting parties through the mobilization of social norms. The normative dimension introduced in HM2008 epitomizes a break with the strictly calculative world of mainstream economics. It implicitly involves rather than ignores the social matrix in which contracts are established by implicitly recognizing the role of binding and regulatory norms external to the contract. Thus conceived, contracts are social constructions and the impact of the relational particularities of a given type of contract must then be incorporated in the analysis.

Macneil considers that contracts can be established and governed efficiently only if the parties adopt a consciously cooperative attitude, ie, if they consciously renounce to maximizing utility in the short run in order to allow for the transaction to yield the maximum exchange surplus in the long run (Campbell, 2001). Indeed, relational contracts, in law as in mainstream economics (Baker et al, 2002), are basically defined by their long-term character and by their being based in informal agreements. Both relational contracts literatures consider that when people interact over time, threats, promises and commitments concerning future behavior

\footnotetext{
${ }^{6}$ We rely on Campbell (2001)'s account of Macneil's theory of relational contracts. This theory depicts contracts as positioned in a spectrum from almost purely discrete contracts to almost entirely relational ones; the employment contract locates at the relational end of the spectrum.

7 It is worth noting that, in HM2008, unlike performance, the price/wage is "objectively" set by the competitive market. Prices and wages are then shielded from subjective and normative valuations.
} 
influence current behavior, which renders them self-enforcing. Economists use repeated-games models to analyze relational contracts (Gibbons, 1997; Baker et al, 2002). The logic is that the shadow of the future subdues the temptations of the present. Cooperation becomes the optimal strategy if the present value of the current and future payoffs from cooperation exceeds the present value of the higher current payoff from defection followed by the lower payoff from punishment. HM2008 and Hart (2002) explicitly denounce relational models; in their view, they provide a false because utopian solution to the issue of contract enforcement. Repeated interactions do not solve the opportunism issue and their theory of contracts as reference points is explicitly proposed as a firmer alternative solution to the enforceability issue.

Notwithstanding, conceiving employment relationships as relational contracts capture some of their important features. Employment relationships - with a growing number of exceptions, to be fair - are usually of a long-term and open-ended nature. For a large part, their effective economic efficiency derives from the substantial relationship-specific investments made by both parties, which provide powerful incentives to comply with "reciprocal commitments". But the superior efficiency of employment relationships when compared to commercial contracts also comes from what is emphasized in the relational contracts literature, namely that the relational norms, unwritten codes of conduct and shared understandings which emerge from frequent interaction contribute to preserving the relation and facilitate cooperative adjustment. And frequent interaction is heightened by employees being integrated into an organization.

Even Hart and Holstrom (2010:510) claim that the frequent interactions occurring in workplaces deserve further study since they may foster a "common vision that aligns interests" or "a concern for the workers' well-being". Supplying a "satisfying exchange relation" was pointed out by Williamson (75:38) as being part of the economic problem. In the same vein, Kreps (1996) identifies several phenomena that need theoretical scrutiny, namely the social embeddedness of the employment relationship, its gift-exchange dimension (following Akerlof, 1982), and the "escalating commitments" that accompany long-term relationships. Much of these phenomena are captured by the relational contract literature.

However, the economics relational contract approach is far from exhausting all the relevant aspects of employment relationships. Firstly it sidesteps the inequality of bargaining power that explicitly distinguishes in law the employment from commercial contracts and in firms the decision power of non-human assets owners relative to that of human assets owners (to use established economic terminology). We return to that point later. Secondly, given that the economics relational approach is meant to encompass contracts within firms as well as 
between firms (Gibbons, 2005; Baker et al, 2002) it discards the personal nature of employment relationships.

As referred, neither party reneges on her commitments because of the future value of the relationship, which means that the self-enforcing propriety of relational contracts lies on utility calculations, nothing more. Relational models suppose that informal means of communication (unwritten behavioral rules, shared understandings) are used to ensure coordination but the goal pursued is long run self-interest. Both the means, which are informal but not necessarily personal, and the goal of relational contracts are "economic" in the sense defined by mainstream economics, ie, encompassing behavior restricted to self-interest calculations (Gibbons, 1997). In this respect, HM2008 provide a much more interesting account of contracts, one that actually relies on "non-standard" economic human attributes - feelings of entitlement, aggrievement and shading rather than restricted self-interest. In fact HM2008:33 admit that they may be opening a "black box" and wonder whether their approach is "consistent with utility maximizing behavior".

Brodie (2011) emphasizes the fact that employment relationships have very "personal" specificities. He underlines that several courts have recently come to view "the employment contract as governing personal relations" and involving "greater mutual dependence and trust, with a correspondingly greater opportunity for harm or abuse" (Brodie, 2011:6,7).

But what does "personal" specifically mean? The HM2008's assumption that shading and consummate performance are "not contractible" (HM2008:11) provides an illuminating instance. The distinguishing feature of these traits of human behavior is their moral nature, in their negative and positive facets respectively, and this is what is not contractible. The use by social scientists of the notion of "person" rather than "individual" is precisely meant to contemplate the moral dimension and the social constitution of human beings (Harris, 1989). When HM2008 introduce "feelings of entitlement" into the analysis, they are actually bringing in human abilities that go beyond calculative abilities ${ }^{8}$, namely moral abilities - the ability to interpret and judge other's actions. Agents who feel entitled and deceived, who retaliate and compensate possess an anthropological endowment different from that of the homo oeconomicus.

In our view, the micro-foundations proposed by HM2008 represent a really profound break with calculative rationality; the move is surely far less innocuous than intended by the authors. What HM2008 are actually saying is that conceiving coordination among behaviors is

\footnotetext{
${ }^{8}$ It must nonetheless be beard in mind that in HM2008 the feelings of entitlement and the behavior they trigger are exclusively analyzed in terms of utility calculations.
} 
impossible without conceiving coordination among judgments upon behaviors (Favereau, 2005). And the behavior prompted by these judgments can be of a generous - consummate- or mean - perfunctory - nature. That is, these new micro-foundations acknowledge the full range of moral behavior rather than the exclusive immoral facet of opportunism, on which Williamson focused.

To sum up, two particularities of the employment relationship have been examined so far, namely its intensive relational and personal - normative - character The relational aspect emphasizes the potential for self-enforcement (in case employment contracts are long term) while the personal aspect emphasizes the sensitivity to the specific organizational and institutional "atmosphere" in which employment relationships take place (enforcement then depends on whether people feel well or badly treated). However, these features are not specific to employment relationships.

\section{THE TWO UNIQUE SPECIFICITIES OF THE EMPLOYMENT RELATIONSHIP}

\section{Authority, subordination and dependency}

HM2008 introduced new behavioral micro-foundations in the theory of the firm at the cost of abandoning the asymmetry between owners of physical and human assets presupposed in most economic theories of the firm - though to widely varying extents. To examine the asymmetry issue, we follow Coase's recommendation that to soundly approach the employment relationship, we must consider how it is legally defined.

Although some courts tend to now view "the employment relationship as involving elements of common interest and partnership, rather than conflict and subordination" (Brodie, 2011:4), there is no doubt that imbalance of power is an hallmark of employment relations as legally defined. Even though the imbalance hardly exists in some actual specific cases, the control of employers over employees is legitimate. It is not only the distribution of property rights or economic resources which engenders economic power, it is the employment contract itself which is asymmetrical.

Authority, subordination and power in employment relationships have been widely debated in economics; the essential point is that the employer has some discretion to direct certain dimensions of the employee's behavior. Employment law gives the employer certain rights to the "cooperation" of the employee in areas not covered by explicit or implicit 
agreement (Deakin and Wilkinson, 1995), ie, the employee legally subordinates him/herself to the exercise of the employer authority. It is precisely the facts of authority/subordination that contribute to attenuate opportunism since it legitimates the implementation of control, monitoring and dispute resolution devices. Employment relationships are also more efficient than independent contracting because the fact that employers can decide which tasks are to be performed bestows flexibility to management costlessly, ie, facilitates adaptation after uncertainty is resolved (Simon, 1951; Williamson, 1975). In independent contracting, by contrast, tasks are defined in advance and cannot be adjusted to unforeseen circumstances without renegotiation.

It is worth emphasizing that law scholars systematically mentioned that the obligation of cooperation develops, in the employment context, into the requirement of trust and confidence on the part of both parties (Brodie, 2011). Kreps (1996:572) also underlines that insofar as a party A is given decision-making authority over a party B - which puts B in danger of being exploited - party A must be trustworthy and party B must believe that A will not abuse her decision-making rights. Likewise, the employee is supposed to obey the employer's directions partly because of a sense of duty. That is, in law and in Kreps writings (Kreps, 1996; Baron and Kreps, 2012), it is the moral abilities of both parties that are explicitly supposed to ground the enforcement of employment contracts: renouncing on exploiting higher bargaining power on the part of employers and obeying "reasonable" orders on the part of employees.

Another crucial feature of the employment relationship is the fact that most workers are dependent on the relationship with an employer to fulfill three kinds of needs: economic, social and psychological. Labor law tries to mitigate the inequality associated to economic dependency by being a "countervailing force to counteract the inequality of bargaining power which is inherent and must be inherent in the employment relationship" (Brodie, 2011:8). Even when alternative employment opportunities are available, most workers have less bargaining power than prospective employers and quitting engenders substantial costs. The social and psychological dependency results from the functions work came to fulfill in our societies.

\section{The specificity of the object being exchanged: work}

Most economic modeling of the employment relationship assumes that workers are indifferent among a pre-given set of tasks (HM2008; Simon, 1951; and Bolton and Dewatripont (2012) for a survey of the mainstream literature) and Coase (1937) specifies that workers are supposed to obey "within certain limits". It is the indifference assumption and the "within certain limits" condition that we discuss in the present section. Besides, our discussion will take the HM2008 
"feelings of entitlement" behavioral assumption seriously, that is, we assume that workers are endowed with moral dispositions - more precisely, a sense of justice.

A preliminary point to be made is that the employment relationship is a contract established between two deeply dissimilar entities: a person - an employee who will perform the work in and as a person - and an employer - an impersonal entity which pursues economic impersonal goals. As stated by Williamson "the trick is to understand what is being contracted for". In the case at hand, a wage and tasks designed under efficiency constraints are exchanged against the performance of work, ie, a human activity undisputedly considered to be an essential component of one's sense of identity, self-worth and emotional well-being. In democratic liberal societies employees may legitimately nourish certain expectations towards work but these expectations must be confronted with reality. Actually, there has always been a tension across time between what firms/societies need be done and what workers deserve to fulfill their economic, social and psychological needs.

Muirhead (2004) - whose insightful arguments inform part of the discussion below depicts the ideal of a meaningful or fulfilling work. This ideal is a noble and democratic longing "that reflects that part of the human spirit that affirms its dignity" (Muirhead, 2004:8). What is at stake in work is the kind of people one would like to be, the kind of place we would like to be part of, and what we think we deserve. In particular, simply by virtue of the capacities people bear, liberal societies with their democratic ideal make people expect that these capacities be cultivated rather than thwarted and suffocated by the jobs they hold. The relation between employee and employer cannot be that of a person who for money provides any kind of service considered useful to a given organization. This was what Coase certainly meant with its "within limits" condition. Most sociological studies show that workers aspire to pursue a purpose that is both personal and recognized socially as important. For part of the meaningfulness of work lies in its contributing to the larger society; this is what provides the working life with pride and dignity. Workers provide commitment and effort for the sake of "doing their job well", not just for the sake of something outside the work such as money and consumption.

But the promise of work stands a distance from the lived experience of work which often does not and cannot provide the opportunity for individual accomplishment. Work is not actually designed to allow personal fulfillment but rather to match productivity constraints and to meet social needs that sometimes generate dirty, painful and monotonous work. This is what stands at the heart of Muirhead's reflection: the existence of a tension between "personal fit" and "social fit". There is, on the one hand, the expectation of a meaningful and fulfilling work, one that contributes to developing one's distinctive capacities and purposes (the "personal fit"); 
and there are, on the other hand, tasks in society that need be performed (the social fit). Social fit and personal fit are not easily reconciled because, even though work is endlessly differentiated and persons have widely different aptitudes, societies in every age need tasks done that are not fulfilling to do by anyone. ${ }^{9}$

Another issue is the necessity of work: the experience of work is not something we can forgo if we feel like it; for many it is a command rather than an option. This is in tension with the liberal ideal of freedom and it seems to remove any room for the moral evaluation of work, ie, for justice claims about work. However, the fact that in the world of work freedom is always constrained does not imply that we have to abdicate from expecting that work provide us with what we morally deserve - a work that fits us. Nonetheless, when mainstream economics considers that the employee's consent to enter into a subordination relationship is an expression of unrestrained free choice and when it assumes that employees are indifferent to the tasks they are assigned, it is implicitly denying the legitimacy of "fitting work" claims. A given job may have been voluntarily taken, and contribute to economic efficiency, but nonetheless infringe its holder's sense of dignity. Actual consent, because it supposedly involves mutual benefit, does not exhaust the moral issue at hand, that is, the concern with a job addressing one's needs and entitlements.

This is the original insight of HM2008: showing that feelings of entitlements pervade the world of contracts and, therefore, that of work. But in HM2008, entitlements are restricted to the pecuniary compensation for the work done - it is the divergence about the valuation of work that is at stake, not the content of work itself. HM2008, like most economic models, assume that workers are indifferent between a set of pre-given tasks. Their feelings of entitlements assumption never addresses the content of work - the fact that workers are entitled to a "fitting" work.

The specificity of work, ie, the fact that it enables people to satisfy a broad range of social and psychological needs, may mitigate opportunistic behavior and partly account for the observed self-enforcement of employment contracts. But, as underlined by HM2008, performing consummately depends on people feeling that their work provides what they feel they deserve. In our societies, what people feel they deserve is having the opportunity to develop their capacities and a sense of dignity. Otherwise, perfunctory performance becomes the only sustainable outcome and pecuniary motives become the major drivers at work. This would in fact be consistent with the standard "work as a disutility" assumption, but is totally at

\footnotetext{
${ }^{9}$ Muirhead lengthily develops the case of domestic service in ancient Greece, the nineteenth century and contemporary societies. The tension between personal and social fit is not a feature of modern, capitalist societies; two millenniums ago, Aristotle solved the problem of meaningless work by legitimizing slavery.
} 
odds with the demands real world people nourish towards work. For even if work is a necessity, the way it is organized is not; rather the organization of work has always been a matter of social dispute, thus inviting the participation of employees at all decision levels and through different channels.

\section{CONCLUSION}

We began by examining the human traits that the leading mainstream economic theories of the firm consider relevant to understand the functioning of firms. We pointed out that the opportunism assumption - launched by Williamson (1975) and subsequently adopted by all mainstream literature - exclusively contemplates the immoral facet of human behavior. By contrast, the "feelings of entitlement" assumption, advanced by Hart and Moore (2008), acknowledges the possibility of economic agents displaying both the negative and positive facets of moral behavior. The fact that these "non-standard ingredients", which introduce a normative dimension alongside the standard calculative dimension in the conception of economic behavior, were proposed by the most individualistic of all accounts of the firm - the incomplete contract theory approach - is both perplexing and promising.

The main aim of the present paper was to offer tentative responses to our guiding question "why is the transaction of work more efficiently conducted in a firm than a market?" or, termed differently, why is the employment relationship an efficient mode of coordination? To pursue this objective, we outlined a comprehensive account of the specificity of the employment relationship when compared to independent contracting, specificity that we argue goes beyond the transaction cost economizing allowed by the authority/subordination feature of employment relationships.

A brief overview of the relational contract literature, in law and in economics, provides a partial answer to our inquiry: the use of human assets inside organizations is more efficient than outside contracts because it favors "relational contracting". The simple fact that people deal with each other over time - an opportunity offered by the integration into an organization increases the value to each of continuing to interact. It is recognized in this literature that the value of the interaction is distinct from the economic value it generates. But the economics relational contract literature does not do justice to the crucial singularity of the employment contract: the specificity of the object being exchanged.

We then focused on the specificity of work - a subject much less researched in social sciences that it may seem and totally disregarded in economics. Along with its economic role, 
work has an intrinsic value for most workers since it is a source of identity, self-realization and social status. We argue that the fact that people expect work to satisfy a broad range of social and psychological needs ${ }^{10}$ moderates opportunistic behavior at work and motivates consummate performance. Of course, work is a specific human activity both when it is the object of an independent contract and an employment relationship but this does not impedes that it does embody a specificity of the employment relationship. Holmstrom and Milgrom (1994) clearly established that the employment contract is more efficient than independent contracting the more difficult it is to evaluate and measure performance, that is, the more uncertainty there is about the workers' behavior. Stated in different terms, this means that the employment contract is more efficient the greater is the difference between perfunctory and consummate performance.

To sum up, our original responses to our guiding question is that the transaction of work is more efficiently conducted in a firm than a market not just because of the authority/subordination nature of the employment relationship but also because i) "relational contracting" within firms has an intrinsic value that helps enforcing contractual commitments and ii) when provided with the opportunity to satisfy their social and psychological needs, that is, when they feel well treated, workers commit to their work and perform consummately rather than perfunctorily. In any case, to soundly understand the efficiency of the employment relationship, one must go beyond the calculative abilities of homo economicus and endow him with moral abilities.

The trends that mark the recent evolution of the world of work, namely, the erosion of institutional affiliations, the vanishing of legal protection for the most vulnerable (the neither self-employed nor employed), and the individualization and quantification of performance standards and assessments may result in a severe deterioration of relational norms, trustworthiness and a growth of aggrievement feelings. In such circumstances, perfunctory performance might become the standard behavioral norm, with the negative efficiency effects highlighted by Holmstrom and Milgrom (1994). Reputational concerns are often evoked to argue that employers spontaneously resist the temptation to exploit employees (Baron and Kreps, 2012), but what if firms in a given period or in a given place all become exploitative, or if the conditions required to sustain reputation, namely the state of the labour market, are not met?

\footnotetext{
${ }^{10}$ It must nonetheless be noted that not all available and needed jobs are able to fulfill such expectations and requirements. 


\section{REFERENCES}

AKERLOF George (1982): Labor contracts as partial gift exchange, The Quarterly Journal of Economics, 97(4): 543-569.

AKERLOF, Robert (2010): Punishment, compliance and anger in equilibrium, Job Market paper, MIT, unpublished.

ALCHIAN, Armen and H. Demsetz (1972), 'Production, information costs and economic organization', American Economic Review, 62 (5), 777-795.

BAKER, George, Robert Gibbons and Kevin Murphy (2002): Relational contracts and the theory of the firm, The Quarterly Journal of Economics, 117(1): 39-84.

BARON, James and David Kreps (2012): Employment as an economic and a social relationship, in Gibbons R. and J. Roberts (ed.), The Handbook of Organizational Economics, Princeton: Princeton University Press.

BOLTON, Patrick and Mathias Dewatripont (2012): Authority in organizations: A survey, in Robert, Gibbons and John Roberts, (eds.), Handbook of Organizational Economics, Princeton: Princeton University Press.

BRODIE, Douglas (2011): How relational is the employment contract? Industrial Law Journal, 40(3):232-253.

BROUSSEAU, Éric and Jean-Michel Glachant (ed.) (2002): The economics of contracts, Cambridge: Cambridge University Press.

CAMPBELL, David (2001): Ian Macneil and the relational theory of contract, in Macneil and Campbell, The relational theory of contract: Selected works of Ian Macneil, London: Sweet and Maxwell.

CHEUNG, Steven (1983): The contractual nature of the firm, Journal of Law and Economics, 26(1): 1-21. 
COASE, Ronald (1937), 'The nature of the firm', reprinted in The Firm and the Market, Chicago, University of Chicago Press, 1990.

DEAKIN, Simon and Frank Wilkinson (1995): Contracts, cooperation and trust: The role of the institutional framework, ESRC CBR Working-Paper, University of Cambridge.

FAVEREAU, Olivier (2005): The missing piece in rational choice theory, Revue Française de Sociologie, 46: 103-122.

FEHR, Ernst, Oliver Hart and Christian Zehnder (2011): Contracts as reference points Experimental evidence, American economic Review, 101: 493-525.

FEHR, Ernst, Oliver Hart and Christian Zehnder (2009): Contracts as reference points and competition, Journal of the European Economic Association, 7(2-3): 561-572.

GIBBONS, Robert (2005): Four formal(izable) theories of the firm? Journal of Economic Behavior and Organization, 58:200-245.

GIBBONS, Robert (1997): An introduction to applicable game theory, Journal of Economic Perspectives, 11: 127-149.

HARRIS, Grace (1989): Concepts of individual, self, and person in description and analysis, American Anthropologist, vol. 91, pp. 599-612.

HART, Oliver (2008): Reference points and the theory of the firm, Economica, 75:404-411.

HART, Oliver (2002): Norms and the theory of the firm, University of Pennsylvania Law Review, 149:1701-1715.

HART, Oliver and Bengt Holmstrom (2010): A theory of the firm scope, The Quarterly Journal of Economics, 125(2): 483-513.

HART, Oliver and John Moore (2008): Contracts as reference points, The Quarterly Journal of Economics, 123(1): 1-48.

DINÂMIA'CET - IUL, Centro de Estudos sobre a Mudança Socioeconómica e o Território 
HOLMSTROM, Bengt (1999): The firm as a subeconomy, Journal of Law, Economics and Organization, 15: 74-102.

Holmstrom, Bengt and Paul Milgrom (1994): The firm as an incentive system, The American Economic Review, 84(4): 972-991.

JENSEN, Michael and H. W. Meckling (1976), 'Theory of the firm: managerial behavior, agency costs and ownership structure', Journal of Financial Economics, 3 (4), 305-60.

KREPS, David (1996): Markets and hierarchies and (mathematical) economic theory, Industrial and Corporate Change, 5(2): 561-595.

MASTEN, Scott (1988): A legal basis for the firm, Journal of Law, Economics and Organization, 4(1):181-198.

MUIRHEAD, Russell (2004): Just work, Cambridge: Harvard University Press.

SIMON, Herbert (1951): A formal theory of the employment relationship, Econometrica, 19(3): 293-305.

WILLIAMSON, Oliver (1983, first edition 1975): Markets and hierarchies, New-York: The Free Press. 